\title{
Fashion lab como fator de inovação no design autoral de moda
}

\section{Alessandro Mateus Felippe}

Mestrando, Universidade do Estado de Santa Catarina Orcid: 0000-0001-6856-3991/ lattes

\section{Sandra Regina Rech}

Doutora, Universidade do Estado de Santa Catarina Orcid: 0000-0002-0062-6914/ lattes

\section{Icléia Silveira}

Doutora, Universidade do Estado de Santa Catarina Orcid: 0000-0003-4493-9768/ lattes

\section{Lucas da Rosa}

Doutor, Universidade do Estado de Santa Catarina Orcid: 0000-0002-8429-2754/ lattes 


\title{
Fashion lab como fator de inovação no design autoral de moda
}

\begin{abstract}
RESUMO
As transformações oriundas pós-revolução industrial seguem ecoando em nossa sociedade, permitindo avanços na área de tecnologia, produção e consumo de produtos em diferentes segmentos, em especial o da moda. Diante disto, o presente artigo propõe compreender, de forma inicial e conceitual, a utilização do espaço Fashion lab por designers autorais de moda. Considera-se que o uso desse laboratório pode qualificar o processo de inovação durante a produção de novos produtos. Neste trabalho, utilizou-se a pesquisa básica com abordagem qualitativa descritiva e a fundamentação teórica contempla os conceitos de inovação, fab lab, Fashion lab e design autoral. Por fim, os resultados da pesquisa indicam que os princípios de compartilhamento, experimentação e prototipação corroboram para a inovação no design autoral de moda em fashion labs.
\end{abstract}

Palavras-chave: Fashion lab. Design autoral. Inovação. 


\title{
Fashion lab as a factor of innovation in fashion authoring design
}

\begin{abstract}
The post-industrial revolution transformations continue to echo in our society, allowing advances in the area of technology, production, and consumption of products in different segments, especially fashion. In view of this, this article proposes to understand, in an initial and conceptual way, the use of space Fashion lab by fashion designer designers. It is considered that the use of this laboratory can qualify the innovation process during the production of new products. In this work, the basic research was used with a descriptive qualitative approach and the theoretical foundation contemplates the concepts of innovation, fab lab, fashion lab, and authorial design. Finally, the research results indicate that the principles of sharing, experimentation, and prototyping corroborate to the innovation in fashion authoring design in fashion labs.
\end{abstract}

Keywords: Fashion Lab. Authorial Design. Innovation. 


\title{
El laboratorio de moda como factor de innovación en el diseño de moda de autor
}

\begin{abstract}
O
Las transformaciones derivadas de la revolución postindustrial continúan resonando en nuestra sociedad, permitiendo avances en el área de tecnología, producción y consumo de productos en diferentes segmentos, especialmente moda. Ante esto, este artículo se propone entender, de forma inicial y conceptual, el uso del espacio del laboratorio de moda por parte de los diseñadores de moda. Se considera que el uso de este laboratorio puede calificar el proceso de innovación durante la producción de nuevos productos. En este trabajo se utilizó la investigación básica con un enfoque descriptivo cualitativo y la base teórica contempla los conceptos de innovación, fab lab, Fashion lab y diseño de autor. Finalmente, los resultados de la investigación indican que los principios de compartir, experimentación y creación de prototipos corroboran la innovación en el diseño de moda de autor en los laboratorios de moda.
\end{abstract}

Palabras clave: Laboratorio de moda. Diseño. Innovación. 


\section{INTRODUÇÃO}

De forma histórica, a Revolução Industrial - ocorrida na Europa no século XVIII - trouxe grandes mudanças na lógica de se organizar a concepção, a distribuição e o consumo de bens, com destaque à concentração dos meios de produtivos nas mãos de conglomerados industriais. Entretanto, quando se visualiza a última década, percebe-se que a disseminação da tecnologia, dentro de um contexto consolidado da Sociedade da Informação (CASTELLS, 2009), corroborou com mudanças na sociedade ocidental, resultando em alterações nos modos de produção vigente, consumo de bens e o próprio gerenciamento da vida social.

A partir deste contexto, diversas indústrias precisaram se remodelar para acompanhar tais transformações. A indústria da moda, historicamente influenciada por alterações sociais, mais uma vez precisa galgar esforços para absorver as principais mudanças que estão acontecendo, manifestadas em lógicas do consumo colaborativo, produtos vistos como sustentáveis, consumidores com anseios particulares, fast fashion versus slow fashion, open design (processo de design com a livre participação desde a fase de criação), produção em pequena escala etc.

Além de mudanças industriais, o que se percebe também é uma alteração no papel cumprido pelos consumidores: estão mais atentos, mais autorais, mais ousados, ou seja, há a ascensão de consumidores travestidos de produtores de bens e serviços, sugerindo uma nova lógica de se produzir e consumir. Em paralelo a isto, aspectos como 0 empreendedorismo e o acesso facilitado a novas tecnologias dão o tom de um novo cenário, o qual dá vazão para surgir o Movimento Maker, que emerge como resposta à crise econômica mundial, sublinhado por um protagonismo criativo 
e de conhecimento, no qual dá a condição das pessoas realizarem com as próprias mãos projetos pessoais, experimentais e inovadores (ANDERSON, 2012; SILVA, 2017; SILVA; SILVEIRA, 2018). Essas diferentes concepções são feitas de forma coletiva ou individual, sem - necessariamente - estarem ligados a uma organização, fortalecendo cada dia mais a chamada cultura maker na esfera social.

Em sintonia com a descentralização dos meios de produção observada na última década, surgem espaços para suprir as necessidades de trabalho dos makers, tais como os makerspaces ou hackerspaces (ANDERSON, 2012). A partir disto, existem os chamados fab labs que dão a condição do sujeito criativo (FLORIDA, 2011) explorar diferentes tecnologias e maquinários em prol de seus projetos, além de serem abertos ao público e terem valores amparados na colaboração e experimentação. Ao se pensar na produção da moda, há os fashion labs (laboratórios de moda), que se configuram como ambientes que unem diferentes tecnologias e maquinários com a fabricação digital da moda, permitindo um acesso mais democrático a toda comunidade.

Tendo em vista todos os aspectos descritos até então, o problema de pesquisa desse artigo se configura em: como o espaço Fashion lab pode contribuir para a inovação no design autoral de moda? Em outras palavras, a intenção do presente artigo é compreender se a utilização de fashion labs por designers autorais de moda pode contribuir para a inovação no processo de concepção de novos produtos a partir de aspectos e características desses espaços.

Os passos metodológicos, em termos de classificação, têm como finalidade a pesquisa básica, com abordagem qualitativa e propósito descritivo. Do ponto de vista dos procedimentos técnicos, vale-se da metodologia de revisão bibliográfica, buscando uma articulação teórica e conceitual 
entre os diversos autores a fim de atingir a intenção do estudo a partir da resolução do problema exposto anteriormente.

De forma estrutural, faz necessária a definição do conceito de inovação segundo Bertoni e Moura (2016), Manual de Oslo (2005) e Manzini (2008), conceito de designer autoral por meio das reflexões de Baxter (2011), Sohn, Laste e Rios (2017), Parode e Scaletsky (2009) e Gonçalves (2014), conceito de fab lab a partir da definição de Eychenne e Neves (2013), Silva e Silveira (2018), Silva (2017), Anderson (2012), Teixeira, Almeida e Ferreira (2016), Jackson (2018) e o conceito de Fashion lab mediante a perspectiva da Textile Academy (2018), Bastos (2014) e a TCBL (2018). Posteriormente, será realizada uma investigação conceitual na qual busca-se compreender a importância das características de um espaço de Fashion lab para designers autorais de moda para inovação a partir dos princípios do compartilhamento, experimentação e prototipagem.

Por fim, esta reflexão configura-se de extrema relevância por investigar alterações tecnológicas, industriais, econômicas, estruturais, dentre outras esferas, para o setor da moda. Além disso, ao fazer a delimitação para o uso de fashion labs por designers autorais, pontua-se as alterações na forma de se pensar e produzir bens de consumo com viés mais exclusivos, indo para o lado oposto da saturação e homogeneização da oferta e consumo da moda a partir do fenômeno do fast fashion.

\section{PASSOS METODOLÓGICOS}

Neste tópico, classifica-se esse artigo em termos científicos através do uso de métodos, técnicas e procedimentos, uma vez que a metodologia científica "se constitui no caminho de construção do método científico" 
(SILVEIRA, 2018, p. 13). Dessa maneira, os passos metodológicos compreendem pesquisa com finalidade básica. Isso porque "objetiva gerar conhecimentos novos úteis para - avanço da ciência sem aplicação prática prevista" (SILVEIRA, 2018, p. 15), através da articulação de autores que pesquisam as temáticas de inovação, fashion labs e design autoral.

Do ponto de vista da abordagem do problema, classificase como qualitativa. Segundo Gil (2008, p. 15), a abordagem qualitativa "considera que há uma dinâmica entre o mundo real e o sujeito", ou seja, busca-se uma interpretação e construção de significados a partir dos dados obtidos ao longo do estudo. Do ponto de vista dos objetivos almejados, consideram-se de cunho descritivo, já que esse tipo "visa descrever as relações entre variáveis" (SILVEIRA, 2018, p. 17) trabalhando com a descrição de algum fato ou fenômeno.

Finalmente, do ponto de vista de procedimentos técnicos, a pesquisa vale-se da metodologia de revisão bibliográfica, buscando uma articulação teórica e conceitual entre os diversos autores a fim de responder a intenção proposta. Segundo Lakatos e Marconi (2017), essa estratégia nos permite entrar em contato com todo referencial teórico publicado, seja em monografias, teses, livros ou mesmo em materiais audiovisuais. Ou seja, através da revisão da bibliografia, pode-se entender o que já foi pesquisado, principais conclusões e oportunidades de novas abordagens sobre um mesmo assunto.

Segundo Stumpf (2010, p. 51), esta metodologia pode ser entendida a partir dos pontos de vista: amplo e restrito. Num sentido amplo, este desenho metodológico se configura como o momento de visualizar a pesquisa de forma global, entendendo o começo, o meio e o fim. Ou seja, planeja-se o que fazer, como fazer e quais conceitos usar. Por fim, realiza- 
se a síntese de tudo que é necessário para desenvolver a proposta de pesquisa através de um texto acadêmico, com a inclusão das ideias e interpretações do pesquisador.

Num sentido restrito, Stumpf (2010, p. 51) argumenta que é importante se debruçar de forma mais intensa sobre teorias, autores e abordagens que contribuam de forma objetiva na resolução da problemática estabelecida. Através de resumos e fichamentos, obtém-se embasamento teórico para argumentação e fundamentação de reflexões, sendo possível concordar ou discordar dos dados levantados ao longo do processo metodológico.

Numa abordagem estrutural, após a revisão dos conceitos de inovação, fab lab, Fashion lab e design autoral, entendese as características dos laboratórios de moda através de uma síntese materializada em três princípios: a colaboração, a experimentação e a prototipação. A partir deles, propõe-se uma triangulação conceitual com os tipos de inovação estabelecidos pelo Manual de Oslo (2005), a fim de compreender como o Fashion lab pode contribuir para a inovação no processo de design autoral de moda com abordagem teórica.

\section{FUNDAMENTAÇÃO TEÓRICA}

\subsection{Inovação}

O conceito de inovação é interdisciplinar e sua origem é um tanto indefinida, uma vez que diferentes áreas se apropriaram desse termo, gerando interpretações próprias e distintas (BERTONI; MOURA, 2016). Neste estudo, busca-se explorar algumas abordagens da ideia de inovação, sintetizando as principais características deste substantivo multifacetado. 
Para pensar sobre inovação, torna-se crucial refletirmos acerca da ideia de criatividade e a interlocução entre esses dois conceitos. Neste sentido, Hartley (2005) defende que o homem por si só é criativo e Howkins (2007) sublinha que a sociedade deixou se simplesmente processar informações para usá-las em prol da criatividade. Além disso, o autor acredita que nossa sociedade começou a valorizar a geração de ideias, percebendo nesse fenômeno uma nova relação entre economia e criatividade, visto que o homem está ganhando dinheiro com suas ideias (HOWNKINS, 2007).

Paralelamente a isso, a valorização de bens intangíveis é algo recente e está correlacionada ao que Florida (2011) denomina como difusão da inovação. Quer dizer, o conhecimento e a informação são artefatos usados para catalisar a criatividade; já a materialização e difusão destas ideias é denominado de inovação, sendo visualizada em forma de artefatos, bens e serviços. Em suma, é possível destacar que a criatividade é algo intangível, está no campo das ideias, a inovação é tangível, físico, palpável e que um momento é sucedido pelo outro.

Considerando o objetivo deste estudo, que é entender de que forma os fashion labs podem contribuir na inovação de produtos por designers autorais de moda, busca-se expandir o conceito de inovação, a partir do Manual de Oslo (2005, p. 55), definindo como:

[...] a implementação de um produto (bem ou serviço) novo ou significativamente melhorado, ou de um processo, ou um novo método de marketing, ou um novo método organizacional nas práticas de negócios, na organização do local de trabalho ou nas relações externas.

A partir disso, compreende-se que o conceito de inovação existe a partir das atividades, métodos e processos empreendidos na concepção de um produto/serviço/bem 
final. Por isso, "uma empresa inovadora é aquela que implementou uma inovação durante um período de análise" (MANUAL DE OSLO, 2005, p. 55). Ainda segundo o Manual de Oslo (2005), existem quatro tipos principais, como demonstra o Quadro 1.

Quadro 1. Tipos de Inovação

\begin{tabular}{|l|l|}
\hline Tipo de Inovação & Definição \\
\hline De produto & $\begin{array}{l}\text { Introdução de um bem ou serviço novo ou significativamente } \\
\text { melhorado no que concerne a suas características ou usos previstos. } \\
\text { Incluem-se melhoramentos significativos, em especificações técnicas, } \\
\text { componentes e materiais, softwares incorporados, facilidade de uso ou } \\
\text { outras características funcionais. }\end{array}$ \\
\hline De processo & $\begin{array}{l}\text { Implementação de um método de produção ou distribuição novo ou } \\
\text { significativamente melhorado. Incluem-se mudanças significativas em } \\
\text { técnicas, equipamentos e/ou softwares. }\end{array}$ \\
\hline De marketing & $\begin{array}{l}\text { Implementação de um novo método de marketing com mudanças } \\
\text { significativas na concepção do produto ou em sua embalagem, no } \\
\text { posicionamento do produto, em sua promoção ou na fixação de preços. }\end{array}$ \\
\hline Organizacional & $\begin{array}{l}\text { Implementação de um novo método organizacional nas práticas de } \\
\text { negócios da empresa, na organização do seu local de trabalho ou em } \\
\text { suas relações externa. }\end{array}$ \\
\hline
\end{tabular}

Fonte: MANUAL DE OLSO (2005, p. 57-61), adaptado por Silva, 2018, p. 96.

Refutando as verdades disseminadas no senso comum, nas quais afirmam que um produto ou processo dito inovador precisa ser revolucionário ou totalmente disruptivo, aqui é possível entender que esse conceito pode se traduzir no melhoramento de um produto, processo, serviço, espaço. Com foco específico, as inovações de produtos "podem utilizar novos conhecimentos ou tecnologias, ou podem basear-se em novos usos ou combinações para conhecimentos ou tecnologias existentes" (MANUAL DE OSLO, 2005, p. 57). Logo, é possível compreender que podem ser propostas inovações do tipo incremental (pequenas modificações ao longo do processo de concepção do produto), ou do tipo radical (implicando alterações totais se comparados a produtos produzidos previamente). 
Dentre as inúmeras possibilidades de se pensar e fazer inovação, eis que há um tipo específico que se manifesta frente a complexidade do mundo: a inovação social. Segundo Manzini (2008, p. 61-62), o termo diz respeito a um novo comportamento que indivíduos e comunidades adotam frente aos seus problemas locais e são guiados por "processos organizacionais 'de baixo para cima' em vez daqueles 'de cima para baixo'", demonstrando uma nova forma de articular todos os sujeitos envolvidos. Além disso,

[...] designers têm a missão de facilitar a convergência dos diferentes parceiros em torno de ideias compartilhadas e potenciais soluções. Esse tipo de atividade requer uma série de novas habilidades de design: promover a colaboração entre diferentes atores sociais (comunidades locais e firmas, instituições e centros de pesquisa); participar na construção de visões e cenários compartilhados; e combinar produtos e serviços já existentes para suportar a específica comunidade criativa com a qual colaboram (MANZINI, 2008, p. 28).

Isto posto, aqui se estabelecem duas relações principais entre o processo de inovação para com o design social. A primeira diz respeito a atividade de design ser vista como mediadora entre tecnologia, problemas sociais e a geração de ideias para haver a inovação (seja em produtos, processos, marketing ou organizações). A segunda é vista na medida em que o conceito de design social olha para uma esfera social local na procura por processos inovadores, conectando sujeitos envolvidos em alto ou baixo grau com o problema a ser solucionado por meio de uma metodologia própria, proposto em seis etapas: inspiração, propostas, prototipagem, sustentação, difusão e mudança sistêmica (HUGO; MOURA, 2015).

Neste estudo, em síntese, o processo de inovação, para ocorrer na prática, tem como pressuposto a criatividade que 
pode ser vista em quatro tipos (produto, processo, marketing, organização) e pode ser usada para resolução de problemas locais a partir do design social. A seguir, reflete-se acerca do conceito de design autoral, sublinhado como importante para a discussão posterior.

\subsection{Design autoral}

Devido a industrialização global e a chamada democratização no acesso a bens de consumo a uma grande parcela da população, os consumidores agora possuem o poder de escolha no momento de consumir. Conforme afirma Baxter (2011, p. 17), "um fabricante, que não seja capaz de se mover com rapidez suficiente nesse novo mundo de negócios, pode ficar seriamente comprometido", contrastando com momentos passados de escassez monetária e de opções de produtos e serviços.

Neste novo paradigma, sublinha-se que 0 desenvolvimento de novos produtos por marcas, fábricas e designers não é tarefa fácil. Isso "requer pesquisa, planejamento cuidadoso, meticuloso e, mais importante, o uso de métodos sistemáticos" (BAXTER, 2011, p. 19). Através disso, as metodologias para criação de produtos necessitam uma abordagem, organização e prática interdisciplinar, dialogando com aspectos do marketing, engenharia, estética, tecnologia, psicologia, dentre outros. Neste sentido, apresentam-se os envolvidos no desenvolvimento de produtos e seus respectivos a seguir:

Quadro 2. Atores envolvidos no desenvolvimento de produtos

Atores

Consumidores
Desejos

Desejam novidades e produtos melhores a preços razoáveis. 


\begin{tabular}{|c|c|}
\hline Vendedores & Desejam diferenciações e vantagens competitivas. \\
\hline Engenheiros de produção & $\begin{array}{l}\text { Desejam simplicidade na fabricação e facilidade de } \\
\text { montagem. }\end{array}$ \\
\hline Designers & $\begin{array}{l}\text { Desejam experimentar novos materiais, processos e } \\
\text { soluções. }\end{array}$ \\
\hline Empresários & $\begin{array}{l}\text { Desejam poucos investimentos e retorno rápido do } \\
\text { capital. }\end{array}$ \\
\hline
\end{tabular}

Fonte: BAXTER (2011, p. 11), adaptado pelos autores.

Para alinhar os envolvidos elucidados no quadro 2 com o foco desta pesquisa, duas observações são importantes. A primeira considera consumidores que pertencem ao universo do consumo autoral; isso significa que são consumidores que, além de desejarem novidades e produtos melhores a preços razoáveis, procuram produtos relacionais, criativos, culturais e com valor visual (MORACE, 2018). A segunda diz respeito aos designers que projetam para uma fabricação autoral; por isso, não pertencem a atividades com foco no design corporativo, "não permitindo que o trabalho do designer tenha resultados tão livres" (SOHN; LASTE; RIOS, 2017); neste sentido, o escopo do estudo entende atividades e produtos desenvolvidos através do design autoral.

Dessa forma, o design autoral pode ser visto como uma atividade que se manifesta frente a uma sociedade pósindustrial, com oferta de produtos saturados e massificados cultural e esteticamente (SOHN; LASTE; RIOS, 2017). Ou seja, correspondendo a um desejo do homem de se distinguirse através da compra de bens (seja no segmento de transporte, vestuário, lazer, casa...), os sujeitos consumidores autorais podem transgredir e romper (temporariamente) as regras de uma sociedade massificada (MORACE, 2018; GONÇALVES, 2014).

Segundo Gonçalves (2014, p. 53), "o design autoral se apresenta carregado de significados impostos aos artefatos pelo criador, e se configura, portando, como agenciador de 
novos valores". Tal objetivo se conquista pela produção em pequena escala, com características exclusivas, uma vez que "o design de autor serve para produzir sensações nos corpos a partir dos objetos como serve para distingui-los através de cargas simbólicas que Ihe são agregadas, projetando-as ao plano das relações sociais" (PARODE; SCALETSKY, 2009, p. 97), o que implica numa prática diferenciada e, por vezes, estratégica, frente aos novos hábitos de consumo.

Ainda segundo Sohn, Laste e Rios (2017, p. 102),

Pode-se dizer que o design autoral vem ao encontro de uma perspectiva mais inovadora e sustentável em relação a oferta e consumo de produtos e serviços. Estando ligado à produção exclusiva, próxima às características do trabalho artístico. O designer autoral pode ser considerado um artista que busca constantemente a inovação e geralmente produz sempre em pequenas quantidades, focando em um nicho específico do mercado.

Neste sentido, compreende-se que o designer autoral é visto como um agenciador de novos valores, uma vez que ao projetar suas criações, rompe com a lógica homogênea dos produtos disponíveis, seja através do uso de um novo material, resgate de alguma técnica, processo criativo próprio, produção em pequena escala ou mesmo o atendimento a alguma necessidade de um perfil de consumidores não atendido por grandes marcas.

Por fim, registra-se o entendimento do design autoral voltado para o setor da moda e vestuário. Neste caso, o profissional e a atividade também são vistos como mediadores (GONÇALVEZ, 2014, p. 59) para novos significados simbólicos, já que os produtos são resultados de experimentações subjetivas e sociais, implicando no diálogo entre o design autoral com outras referências culturais e de comportamento de consumidores. Em seguida, discute-se o 
terceiro conceito ( $f a b$ labs), percebido como importante para a análise posterior.

\subsection{Fabrication laboratories - fab labs}

A forma de entender o trabalho, juntamente com os respectivos espaços usados para cumprir as jornadas empregatícias, sofreram diversas transformações nas últimas duas décadas. De acordo com Silva e Silveira (2018, p. 132), aspectos como tecnologia, incentivo ao empreendedorismo e surgimento da cultura maker estão moldando novos formatos de se pensar o trabalho e seus ambientes.

Neste sentido, sublinham-se novas características de espaços contemporâneos de concepção de produtos e serviços. Anderson (2012) cita como exemplos os makerspaces ou hakerspaces, concebidos a partir da Cultura Maker , como espaços para inovação, no qual pessoas comuns podem fazer uso de tecnologia para projetarem plataformas, produtos, serviços e soluções através do compartilhamento de ideias, experiências e criatividade.

Esses espaços, percebidos como um reflexo de um novo paradigma social, fortalecem-se a cada dia com o acesso à internet, democratização da tecnologia, compartilhamento de informações e a aposta de metodologias experimentais como condição de produção. Teixeira, Almeida e Ferreira (2016, p. 06) definem esses espaços a partir da nomenclatura de habitats de inovação, visto que são "espaços diferenciados, propícios para que as inovações ocorram, pois são locus de compartilhamento de informações e conhecimento, formando networking, e permitem minimizar os riscos e maximizar os resultados". Ou seja, novos formatos de espaços para serem usados para trabalhar de uma forma criativa, inovadora, tecnológica e experimental ampliam as possibilidades para 
sujeitos criativos, como designers, estudantes, profissionais e pesquisadores.

Considerando as novas e diferentes possibilidades de ambientes, Jackson (2018) versa sobre a categoria específica chamada de coworking. Esse conceito se refere tanto ao espaço físico no qual diferentes pessoas utilizam, quanto a ideia de sujeitos compartilharem ideias, experiências e feedbacks para trabalharem coletivamente numa abordagem intangível, a falta de um espaço físico.

Dessa maneira, enquanto alguns espaços são entendidos como coworking vistos pelas características físicas, exemplo o fab lab, outros são entendidos como tal pela característica intangível da união e conexão de pessoas que trabalham pautadas na troca de ideias, exemplo o coffee shop. Silva e Silveira (2018, p. 135) sublinham que nessas duas possibilidades há o desenvolvimento de projetos inovadores, motivados na política de compartilhamento de ideias e experiências, uma vez que isso "representa a ação das pessoas sobre o espaço geográfico ao constituir o espaço social para a criatividade".

Verifica-se o fab lab como um espaço de inovação no qual é possível encontrar novas formas de se trabalhar e utilizar o respectivo espaço. Isso ocorre na medida em que esse lugar tem características de um coworking, é guiado pela lógica do compartilhamento de ideias, incentivado pela essência da criatividade e estruturado a partir de maquinários tecnológicos. Logo, de acordo com Eychenne e Neves (2013), pode-se compreender um fab lab (ou fabrication laboratory) como uma plataforma de prototipagem rápida de objetos físicos, ou seja, através de maquinário específico e suporte técnico, é viável colocar em prática projetos pessoais ou colaborativos. Os fab labs são inseridos em uma rede mundial que conta com quase duas centenas de laboratórios. 
A rede mundial, a chamada Fab Fundation, é uma organização sem fins lucrativos que foi criada no Center for Bits and Atomos (CBA) do Massachusetts Institute of Technology (MIT) em 2009. De acordo com Eychenne e Neves (2013), um fab lab é destinado a profissionais, estudantes e pesquisadores desenvolverem diferentes projetos com acesso democrático ao espaço e com custo baixo. Esses laboratórios são formados por conjuntos de máquinas de comando numérico de nível profissional. Em outras palavras, máquinas de corte de vinil para fabricação de circuitos flexíveis, máquina para corte a laser usada na produção de estruturas (bi ou tridimensionais), fresadora de alta resolução e impressoras 3D são exemplos de máquinas para a composição física de um fab lab (EYCHENNE; NEVES, 2013).

Para ser viável a reprodução de projetos desenvolvidos em diferentes fab labs, existe um protocolo de processos, maquinários e diretrizes estabelecidas pela Fab lab Fundation. Sendo assim, "o kit padrão de máquinas por comando numérico comum aos diferentes Fab labs permite replicar processos desenvolvidos em qualquer laboratório, independente da sua localização" (EYCHENNE; NEVES, 2013, p. 12), o que facilita a conexão entre diferentes usuários ao redor do mundo.

Em relação ao que pode ser desenvolvido em um fab lab, as possibilidades são múltiplas. É possível desenvolver projetos pessoais e coletivos, soluções que beneficiem a uma comunidade específica, desenvolvimento de protótipos para serem vendidos/reproduzidos posteriormente, dentre outras. Conforme salientam Silva e Silveira (2018, p. 137), "esses projetos desenvolvidos podem ser vendidos ou protegidos por direitos autorais, sendo que o processo e as técnicas devem ser disponibilizados para que outros usuários possam utilizálos em seus projetos". 
Nesse sentido, é possível sintetizar que o propósito de um fab lab é gerar inovação para o benefício social. Por conseguinte, isso ocorre na medida em que esses laboratórios são criados com base no acesso democrático ao espaço, assistência técnica aos usuários por profissionais qualificados e o incentivo ao compartilhamento dos resultados ali desenvolvidos com outras pessoas.

\subsection{Fashion laboratories - fashion labs (laboratórios de moda)}

De forma semelhante aos fab labs, e pautado no fenômeno da descentralização da grande e tradicional indústria, surgem os chamados fashion laboratories - fahion labs para o setor da moda. Esses espaços, compreendidos como laboratórios de fabricação de moda e vestuário, oferecem tecnologia, fabricação digital, maquinário e uma atmosfera propícia para a inovação. Segundo Bastos (2014), um Fashion lab também pode ser chamado de textile lab e oferece acesso democrático aos interessados em fazer uso deste espaço, ilustrando as alterações que a indústria da moda está passando e demonstrando como a mesma está se adequando. Neste estudo, a nomenclatura de textile lab é usada como sinônimo de Fashion lab e se caracteriza como o espaço de interesse para se entender a ideia de inovação.

Observando a trajetória da moda e o panorama atual, é perceptível a necessidade de desenvolver produtos cada vez mais inovadores tanto em termos estéticos como tecnológicos, além de rever métodos e processos, tanto no contexto de ateliês (produção mais artesanal e exclusiva) como da indústria (produção em grande escala) (BASTOS, 2014, p. 4). 
Dessa forma, constata-se que a indústria da moda galga esforços para se adaptar a novas necessidades de consumidores, dialogar com diferentes tecnologias e compreender novos padrões de comportamento da sociedade como um todo. E como já mencionado anteriormente,

\begin{abstract}
A prototipagem rápida e o surgimento de espaços alternativos, como a rede internacional de Fab labs, favorecem o compartilhamento de ideias, projetos e experiências e além disso fomentam movimentos que propõem uma direção alternativa à produção em série e à cultura de massa, apresentando possibilidades para uma produção mais exclusiva (BASTOS, 2014, p. 4).
\end{abstract}

Por consequência, as características de compartilhamento de ideias, a democratização do acesso a esses espaços e a experimentação como condição de produção definem esses espaços. Com isso, salienta-se que a aproximação existente entre a concepção de produtos e o universo digital/tecnológico e a relação disso para com designers impulsionou novas formas de trabalho, visto que hoje esses profissionais podem estar conectados em qualquer lugar do mundo para conceberem seus produtos como contextualizado por Silva (2017) anteriormente.

Ainda relacionando a moda com os fab labs, em 2014, a rede mundial de laboratórios mapeou 267 espaços em funcionamento; destes, apenas $16 \%$ estavam desenvolvendo projetos relacionados com moda (BASTOS, 2014, p. 110). Quer dizer, apesar destes laboratórios oferecem maquinário e tecnologia, a indústria da moda é vista como área que está demorando para olhar isso - quando comparada com setores como engenharia, arquitetura e biologia.

Gwilt (2014) e Fletcher (2008) comentam que a criação de ambientes colaborativos para manufatura de bens de vestuário e moda é uma alternativa para a produção em série 
resultado do fast fashion, além de fazer uso de métodos de fabricação digital. Neste contexto, Bastos (2014) menciona que esses espaços podem ser chamados de laboratórios de moda ou textile labs.

Em relação a conjuntura brasileira, a oferta e procura de espaços assim ainda é pequena. Em São Paulo há o LabFashion e o Ateliê Vivo, em Porto Alegre existe o Clube de Costuras Livre e Blumenau há o Fashion lab - coletivo criativo. Nesse sentido, pontua-se que o surgimento de espaços assim para a moda é resultado da busca de profissionais e algumas organizações irem contra a superprodução industrial da moda, através do pensamento colaborativo, uso de novas tecnologias e uma produção não homogenia (como a indústria do fast fashion). Logo, é dentro deste contexto que surge o TCBL, descrito como um conjunto de diferentes empresas, consultores, laboratórios de inovação e tecnologia com vistas a motivar a transformações no cenário atual das indústrias e fábricas têxteis/moda e foi criado pela União Europeia em 2015 (TCBL, 2018).

Segundo a plataforma da TCBL, os laboratórios que oferecem tecnologia, maquinário e infraestrutura para produção em pequena escala, uso de tecnologia paras solução de diferentes problemas e o compartilhamento e conexão de ideias tem um papel fundamental na cadeira TCBL. Dessa forma, a inovação, a experimentação e o empreendedorismo podem ser materializados (TCBL, 2018).

De forma pragmática, para se compreender o espaço de um fashion lab, parte-se do protocolo elaborado pelo MIT que projeta um fashion lab; posteriormente, inclui-se maquinários e infraestrutura necessários para se produzir moda. Dessa forma, para pensar o espaço fashion lab, de acordo com o TCBL e o Textile Academy (2018), são necessários máquinas de costura reta, overloque e tricô, material para 
biolaboratório, material para circuitos em tecido como linhas e tecidos condutivos, software para desenvolvimento de projetos e matérias básicos de costura (tesouras, linhas, tecidos, réguas...).

Apesar das diferentes nomenclaturas, nesta pesquisa se propõe a adoção do termo Fashion lab para se referir a espaços entendidos como laboratórios onde é possível pensar e fazer moda, usar equipamentos que são encontrados em fab labs (impressora 3D, fresadora...) e equipamentos específicos para conceber produtos de vestuário e moda (máquina reta, overloque, tecidos, linhas...). Por fim, num fashion lab é possível produzir produtos em pequena escala, exclusivos e com aspectos inovadores (seja pelo uso de uma tecnologia específica, seja pela solução encontrada para um problema através da experimentação).

\section{PRINCÍPIOS DE INOVAÇÃO DOS FASHION LABS}

Como visto anteriormente, os ambientes chamados de fashion lab são construídos com maquinários específicos para realizar projetos coletivos ou individuais para o setor de vestuário e moda. De forma sequencial, eles são oriundos dos chamados fab labs, possuem acesso democrático de diferentes sujeitos (profissionais, estudantes, pesquisadores), são projetados com a intenção de facilitar e impulsionar a colaboração, o compartilhamento, a prototipação de bens e os processos de criatividade e inovação.

Neste sentido, propõe-se a síntese de três principais princípios de um fashion lab para pensar a inovação considerados relevantes ao longo do estudo: compartilhamento, (b) experimentação e (c) prototipação. A partir de agora, explora-se cada princípio de forma individual, compreendendo e argumentando de que forma é possível 
pensar a inovação para o designer autoral de moda a partir de cada um.

\subsection{Princípio do compartilhamento}

$\mathrm{O}$ ato de compartilhar, segundo autores que pesquisam fab labs e fashion labs, é importante visto que ao desenvolver projetos nesses espaços, acontece a troca de ideias com outros usuários sobre o seu trabalho e dos demais. A partir disso, resultante do ato de se comunicar, os atores envolvidos no design autoral, por exemplo, podem contribuir com know how e expertises específicos (EYCHENNE; NEVES, 2013). Além disso, o ambiente como um todo é compartilhado. Isso significa que através do acesso democrático de diferentes estudantes, pesquisadores e profissionais pode acontecer a troca de feedbacks, a resolução de dúvidas por parte daqueles que não possuem conhecimento aprofundado num maquinário ou tecnologia específica, a construção de networking e a troca de diferentes experiências (SILVA; SILVEIRA, 2018; SILVA, 2017).

Por fim, entende-se que o princípio do compartilhamento de ideias, métodos, projetos e feedbacks por usuários de fashion labs é um valor relevante ao se pensar inovação no design autoral. Isso porque pode-se qualificar projetos de produtos desenvolvidos nestes espaços, permite-se compreender melhor o uso de diferentes tecnologias a serem inseridas no processo de design e encontram-se novos olhares para demandas de mercado, novos comportamentos e tendências a partir da colaboração entre os sujeitos que fazem uso deste ambiente. 


\subsection{Princípio da experimentação}

A experimentação como condição no processo de design autoral em fashion labs é o segundo princípio explorado. Isso porque a ideia de experimentar também é um valor importante nestes ambientes, através do conhecimento e descoberta de novos maquinários e tecnologias em abordagens metodológicas práticas, o uso experimental do espaço e a gestão flexível da equipe envolvida no projeto. Quer dizer, a experimentação é uma forte característica dos laboratórios de moda.

Sendo assim, a ação de experimentar se aproxima do design autoral na medida em que essa prática de design é feita de forma não setorizada e tradicional como em grandes fabricas, por exemplo. Com isso, mesmo havendo um método próprio do profissional, o fashion lab permite a experimentação de novos processos, produção em pequena escala e exclusiva, o uso e teste de diferentes materiais ao longo do desenvolvimento de um produto, resultando na qualificação e aprimoramento do projeto (GONÇALVEZ, 2014).

Diante do exposto, nota-se que a prática da experimentação possui um significativo valor ao se pensar a inovação, pois há a desconstrução do significado do errar; nesta abordagem, visualiza-se o erro como um meio de chegar em novas soluções para diferentes problemas num processo criativo através da experimentação. Isso não significa inovações disruptivas em torno de um produto, mas sim, adaptações, melhorias e descobertas incrementais durante o processo do design autoral de moda. 


\subsection{Princípio da prototipação}

O último princípio discutido é a prototipação ou prototipagem. Isso vai ao encontro da característica marcante de laboratórios: elaborar, na prática, a ideia do usuário através do fabrique de protótipos e mockups. Nesse sentido, os fashion labs oferecem impressoras 3D, fresadoras, máquinas específicas de costura justamente para ser viável a concepção de um produto, mesmo que de forma experimental, a um baixo custo e de forma rápida (OLIVEIRA, 2016).

Portanto, diferentemente de outros espaços criativos e de inovação, aqui é viável, literalmente, chegar com uma ideia na cabeça e sair com um produto materializado. Isso traz vantagens ao usuário maker, visto que neste processo se detecta possíveis falhas em seu processo e produto com facilidade, permite-se o erro e elaboram diferentes soluções para problemas específicos (TCBL, 2018; BASTOS, 2014). Além disso, é viável prototipar desde o produto pertencente ao trabalho final de graduação, materializar alguma solução para melhorar a usabilidade de algum item de vestuário e até contribuir no processo de design autoral de moda.

Sendo assim, sublinha-se que o princípio da propotipação corresponde a um momento importante no design autoral de moda feito em fashion labs, visto que com isso se facilita o processo de melhoria do produto, adaptação de textura, forma e tamanho, agrega-se a fabricação digital para produtos de moda e exploram-se novas soluções com um custo reduzido para e pelo designer. 


\subsection{Triangulação}

Neste momento, demonstra-se a síntese dos princípios que corroboram para inovação presente em fashion labs que pode ser usado por designers autorais de moda na Figura 1. Após refletir acerca dos princípios de modo individual, agora mesclam-se os três a fim de se compreender melhor as razões de uso de um designer autoral de moda de fashion labs buscando inovação.

Figura 1. Triangulação dos princípios para inovação

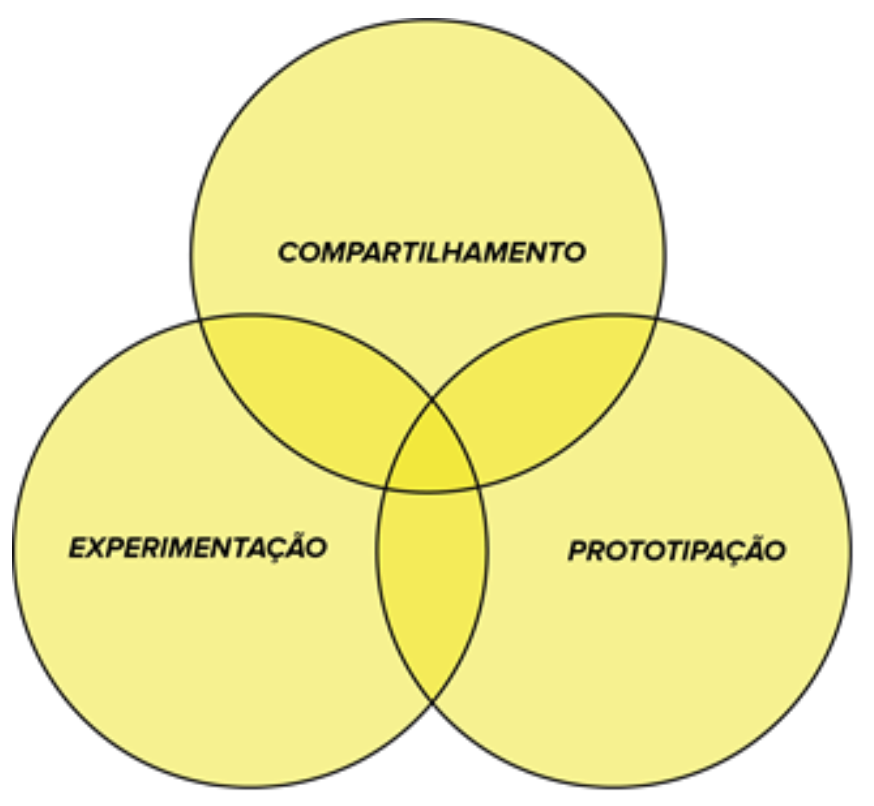

Fonte: elaborado pelos autores (2019).

Destaca-se que, em maior ou menor grau, é possível correlacionar os princípios com as categorias de inovação abordada pelo Manual de Oslo (2005). Dessa forma, a inovação de produto pode ser motivada pela experimentação de novos materiais, o compartilhamento de feedbacks com outros profissionais e a prototipação do mockup de um acessório de moda pela fabricação digital. A inovação de processo pode ser influenciada pela experimentação de uma 
nova metodologia projetual e o compartilhamento do processo de elaboração de um produto entre diferentes fashion labs.

$\mathrm{Na}$ inovação de marketing, é possível visualizar o compartilhamento de ideias referentes a um nicho específico de consumidores, a experimentação ao conceber um novo item de vestuário através da co-criação e a prototipagem de diferentes opções de artigos para teste com determinado tipo de público. Por fim, na inovação organizacional, compartilhase o espaço com diferentes usuários que possuem múltiplos conhecimentos e se experimenta diferentes formas de gestão das pessoas envolvidas no processo.

Através dessa triangulação, nota-se que alguns princípios não são contemplados por todas os tipos de inovação, justamente porque essa síntese é o resultado de uma reflexão inicial sobre o tema. E, sem dúvidas, as hipóteses aqui versadas podem não acontecer na prática, o que leva a resgatar-se aquilo que foi salientado no tópico metodologia: esse estudo possui abordagem teórica e pesquisas com finalidade aplicada podem diagnosticar situações diferentes.

Além disso, observando a triangulação dos princípios para inovação, entende-se que a inovação acontece em graus distintos, o que é diretamente proporcional com a quantidade de princípios considerados durante o desenvolvimento de um produto de moda através do design autoral. Quer dizer, quanto maior é o número de princípios presentes, maior será a intensidade da inovação durante o processo realizado dentro do fashion lab.

Isso significa que ao se valer do princípio da prototipação, deixando de lado o compartilhamento e a experimentação, o designer autoral terá um processo inovador de baixa intensidade no resultado final. No sentido oposto, se o designer fazer uso dos três princípios durante seu processo, 
conclui-se que o seu processo terá alcançado uma alta intensidade de inovação. Em síntese, na intersecção dos três princípios (parte central da triangulação) está o maior grau de inovação, destacando os princípios abordados neste estudo específico, no design autoral de moda no ambiente fashion lab.

\section{CONSIDERAÇÕES FINAIS}

Á guisa de considerações finais, entende-se que os fashion labs são vistos como espaços de inovação para se pensar e fazer moda. São ambientes projetados com maquinário e tecnologia para prototipação rápida de objetivos, máquinas específicas para costura e apoiados em diretrizes como colaboração, criatividade e acesso democrático da sociedade. Além disso, após a discussão proposta, é possível inferir que esses ambientes podem contribuir para a inovação no processo do design autoral de moda a partir de três princípios: o compartilhamento, a experimentação e a prototipação.

Ao realizar a triangulação dos princípios sintetizados, contatou-se que eles podem corroborar e incentivar, em maior ou menor grau, nos quatro tipos de inovações propostos pelo Manual do Oslo. Isso acontece na medida em que o princípio do compartilhamento pode ser visto na inovação de produto, de processo, de marketing e organizacional; o princípio da experimentação pode ser visto na inovação do produto, de processo, de marketing e organizacional; e o princípio da prototipação pode ser visto na inovação de produto e de marketing.

Além disso, verifica-se, de forma reflexiva, que o grau de inovação que pode ser alcançado durante o processo de design autoral dentro desses espaços é diretamente proporcional a quantidade e qualidade dos princípios 
considerados. Logo, conclui-se que ao se elaborar um produto de moda usando a abordagem do design autoral, e se valendo da experimentação, do compartilhamento e da prototipação, haverá uma intensidade maior de inovação no resultado final.

Também, a partir do pressuposto de que o design autoral de moda é um processo que gera produtos de características exclusivas, design diferenciado e não homogêneo (como ocorre no slow fashion), conclui-se que a utilização desses laboratórios traz diferentes vantagens aos profissionais de moda. Dentre elas, estimula o diferencial competitivo de designers pela inovação, fortalece pequenas marcas de moda e vestuário e incentiva novas metodologias de pensar e fazer design autoral de moda.

Salienta-se que a proposta e o desenvolvimento deste estudo é de cunho puramente teórico, podendo ser encontrados resultados diferentes dos aqui apresentados em pesquisas com finalidade aplicada que versem sobre a inovação em laboratórios de moda. Por fim, não se busca sanar ou esgotar conceitos e pesquisas sobre o tema, visto que essa é uma pesquisa inicial. Logo, indica-se para trabalhos futuros a validação dos princípios que corroboram para inovação discutidos nesta pesquisa básica, valendo-se de estudos de caso ou entrevistas com designers autorais de moda que fazem usam esses espaços.

\section{REFERÊNCIAS}

ANDERSON, C. Makers: a nova Revolução Industrial. São Paulo: Elsevier Campus, 2012.

BAXTER, M. Projeto de produto: guia prático para o design de novos produtos. 3. ed. São Paulo: E. Blucher, 2011.

BASTOS, V. F. Moda e Fabricação Digital em um contexto Fab lab: equipamentos, métodos e processos para o desenvolvimento de produtos. Dissertação (Mestrado em Design) - Universidade Federal de Pernambuco - Centro de Artes e Comunicação Programa de Pós-graduação em Design. Recife, p. 153. 2014. 
BERTONI, C.; MOURA, H. Por que a economia criativa é sinônimo de inovação? In: Indústrias criativas [recurso eletrônico] / organizadores Cristiano Max Pereira Pinheiro, Maurício Barth - Novo Hamburgo: Feevale, 2016.

CASTELLS, M. A Sociedade em rede. 12. ed. São Paulo: Paz e Terra, 2009.

EYCHENNE, F.; NEVES, H. FAB LAB: a vanguarda da nova revolução industrial. São Paulo: Editorial FabLab Brasil, 2013.

FLETCHER, K. Sustainable Fashion and textiles: Design Journeys. Londres: Sterling. 2008.

FLORIDA, R. A ascensão da classe criativa. Porto Alegre: L\&PM, 2011.

GIL, A. C. Métodos e técnicas de pesquisa social. 5 . ed. São Paulo: Atlas, 2008.

GONÇALVES, A. S. Q. Criação Autoral Na Perspectiva Do Design Estratégico: uma análise de projetos acadêmicos de moda. Dissertação (Programa de Pós-graduação em Design). Universidade do Vale do Rio dos Sinos, 2014.

GWILT, A. A Practical Guide to Sustainable Fashion. 2014.

HARTLEY, J. Creative industries. Malden, MA, Oxford e Victoria: Blackwell, 2005.

HOWKINS, J. The creative economy: how people make Money from ideas. 2nd ed. London: Penguin Books, 2007.

HUGO, M.; MOURA, H. A contribuição do design para a inovação social sustentável. Anais... XI Semana de Extensão, Pesquisa e Pósgraduação - SEPesq. Centro Universitário Ritter dos Reis, 2015. Disponível em: https://www.uniritter.edu.br/xiii-sepesq. Acesso em: 10 nov. 2018.

JACKSON, K. Make space for others. Disponível em: http://www.makingspaceforothers.com. Acesso em: 20 nov. 2018.

MANZINI, E. Design para inovação social e sustentabilidade: comunidades criativas, organizações colaborativas e novas redes projetuais. Rio de Janeiro: E-papers, 2008.

MARCONI, M. de A.; LAKATOS, E. M. Fundamentos de Metodologia Científica. $8^{\circ}$ ed. São Paulo: Atlas, 2017.

MORACE, F. Consumo autoral: os novos núcleos geracionais. Francesco Morace; $4^{\circ}$ ed. São Paulo: Estação das Letras e Cores Editora, 2018.

MANUAL DE OSLO: diretrizes para a coleta e interpretação de dados sobre inovação tecnológica. Publicado pela FINEP (Financiadora de Estudos e Projetos), $3^{\circ}$ ed. 2006.

OLIVEIRA, D. J. L. O uso da Prototipagem e Fabricação Digital no ambiente Fab lab. Dissertação (Mestrado em Design) Programa de Pós-Graduação em Design, Faculdade de Engenharia. Universidade Federal do Rio Grande do Sul, Porto Alegre, 2016. 
PARODE, F. P.; SCALETSKY, C. C. Design de autor: uma outra comunicação desafiando cultura e mídia global. Journal GHREBH, v. 1, n.13, 2009.

SILVA, M. G. e. Ambientes de inovação para a Indústria Criativa. In: Processos e práticas nas atividades criativas e culturais: reflexões e interfaces da comunicação e da indústria criativa/ Marcela Guimarães e Silva, Renata Corrêa Coutinho (org.). Santiago: Oliveira Books, 2017.

SILVA, M. G.; SILVEIRA, A. C. M. Das garagens às cidades: espaços sociais para a indústria criativa. In: Comunicação e Indústria Criativa: políticas, teorias e estratégias/ organizadores Joel Felipe Guindani e Marcela Guimarães e Silva. Jaguarão, RS: CLAEC, 2018.

SILVEIRA, I. Procedimentos Metodológicos de Pesquisa: ciência e conhecimento. Programa de Pós-graduação em Moda, UDESC, 2018.

SOHN, A. P. L.; LASTE, L. N. B.; RIOS, M. A. T. Design autoral: um estudo na região do Vale do Itajaí. In: e-Revista LOGO, v. 6, n. 3, UFSC, $2017 . \quad$ Disponível em: http://incubadora.periodicos.ufsc.br/index.php/eRevistaLOGO/artic le/view/4922. Acesso em: 18 nov. 2018.

STUMPF, I. R. C. Pesquisa bibliográfica. In: DUARTE, Jorge; BARROS, Antonio (Orgs.). Métodos e técnicas de pesquisa em comunicação. 2. ed. São Paulo: Atlas, 2010.

TCBL. Labs. Disponível em: https://tcbl.eu/labs. Acesso em: 25 out. 2018.

TEIXEIRA, C. S.; ALMEIDA, C. G.; FERREIRA, M. C. Z. Habitats de Inovação: alinhamento conceitual. Florianópolis: Perse, 2016.

TEXTILE ACADEMY. About Fabriacademy. Disponível em: http://textile-academy.org/about/. Acesso em: 12 out. 2018. 